\title{
Accessible ESPON knowledge and its application in local and regional context ${ }^{1}$
}

\author{
Magdalena Górczyńska, Mariola Ferenc, Michał Konopski \\ Institute of Geography and Spatial Organization \\ Polish Academy of Sciences \\ Twarda 51/55. 00-818 Warsaw, Poland \\ mgor@twarda.pan.pl,mferenc@twarda.pan.pl,konopski@twarda.pan.pl
}

\section{Stephanie Essig, Jiannis Kaucic and Bernd Schuh \\ Austrian Institute for Regional Studies and Spatial Planning (ÖIR) \\ Franz-Josefs-Kai 27, 1010 Vienna, Austria \\ essig@oir.at,kaucic@oir.at, schuh@oir.at \\ Stefanie Lange Scherbenske and Christian Dymén \\ Nordregio - Nordic Centre for Spatial Development \\ Holmamiralens Väg 10, Skeppsholmen, Stockholm, Sweden \\ stefanie.lange@nordregio.se, christian.dymen@nordregio.se}

\begin{abstract}
The aim of the ESPON Programme is to produce and disseminate scientific information concerning the European space in terms of economy, society, environment, and governance, which is practical for policy and decision makers at the European, national and regional levels. Under the Detecting Territorial Potentials and Challenges project (ESPON DeTeC) materials on the selected methods, which appeared to be most useful for policy makers, have been collected and subsequently verified within regional laboratories conducted in six European regions. The paper presents the process of selecting and validating the methods, as well as the results of regional laboratories and best practices.
\end{abstract}

Keywords: ESPON, ESPON methods, regional laboratories, best practices, ESPON knowledge.

There is an increasing demand among practitioners and policy makers in Europe for innovative and relevant knowledge for detecting territorial potentials and for utilizing the regions' larger territorial context to turn challenges into opportunities. The ESPON 2013 Programme, the European Observation Network for Territorial Development and Cohesion, inspires policy making by providing

\footnotetext{
1 This paper has been developed under the Scientific Platform project Detecting Territorial Potential and Challenges led by Nordregio, Sweden. It has been financed by the ESPON 2013 Programme and its financial support is gratefully acknowledged. Texts, maps and conclusions stemming from research projects under the ESPON programme presented in this paper do not necessarily reflect the opinions of the ESPON Monitoring Committee. (C) ESPON, 2014.
} 
territorial evidence. Making ESPON knowledge more easily accessible for practitioners and policy makers was one of the main objectives of the ESPON DeTeC project (September 2012-March 2014). This article outlines the inventive process from which ten innovative ESPON methods emerged as an attempt to increase the accessibility of ESPON knowledge. The article further critically discusses the applicability of ESPON results by introducing the ESPON methods to practitioners and policy makers working at local and regional levels.

Having said that, ESPON provides a great amount of information and knowledge. However, there is a long way from ESPON projects that produce knowledge and evidence to their application in territorial development processes in European regions. Taking ESPON knowledge into account requires time and resources of practitioners and policy makers who need to pursue their daily tasks in the regions in the first place. This fact puts pressure on ESPON in the sense that it has to be easily accessible, understandable and relevant. ESPON knowledge needs to be easily applicable for practitioners in their daily work. The DeTeC project thus aims at identifying ESPON methods that could help regions detect territorial challenges and potentials. The following chapter outlines how this has been done in the ESPON DeTeC project.

\section{ESPON DeTeC project introduction}

In order to understand how ESPON knowledge can be utilized to detect territorial potentials and challenges it was crucial to link general approaches and methods developed within ESPON to regions and their territorial development. The report from the ESPON Seminar in Malmö 'Regional Use of ESPON Knowledge' (2010) provided an initial outline of how this can be conducted. DeTeC project and Handbook are structured around six territorial approaches ${ }^{2}$ of revealing territorial potentials identified within ESPON Priority 2 Targeted Analysis projects. Based on the above-mentioned, the inventory and systematic review, five distinct territorial approaches ${ }^{3}$ have been identified for detecting territorial potentials and challenges of a region from a European perspective using ESPON knowledge:

- Detecting global and future challenges and potentials of a region,

- Detecting and comparing territorial performance of a region,

- Detecting the functional areas and internal coherence of a region,

- Detecting current and potential external linkages of a region,

- Detecting opportunities for territorial governance of a region.

The territorial approaches are based on knowledge and approaches developed within ESPON and contain different methods, which include indicators that can be further utilized. Each territorial approach contains references to concrete examples of how these methods have been used in different ESPON projects. In coordination with the development of territorial approaches, interesting and innovative methods have been identified through the inventory and systematic review. The focus in reviewing the methods has been the innovative aspect of the ESPON projects, and their relevance for detecting territorial potentials and challenges.

2 1. Exposing characteristics of a region. 2. Indicating performance of a region. 3. Detecting network relations of a region. 4. Detecting the larger functional area a region belongs to. 5. Detecting influences that impose themselves on a region. 6 . Detecting influences a region imposes on other territories.

${ }^{3}$ More in Smas L., Schmitt P., 2014, Making ESPON knowledge more tangible for detecting regional potentials and challenges: five territorial approaches, EUROPA XXI, vol. 25, p. XX - XXX 
In order to identify methods for detecting territorial potentials and challenges, ESPON projects were systematically reviewed through a rigorous process, including different steps; these included the selection of relevant projects, the review and analysis of projects, the identification and specification of methods of analysis, as well as validation and assessment. Scanning Priority 1-4 projects was the first step in order to significantly reduce the number of projects for review and to identify the most relevant projects; i.e. those that were not too narrow and/or too specific in their aim and scope (i.e. focusing on a particular theme, like ESPON ADES with focus on airports, or ESPON SEMIGRA on demography only), or too specifically programme oriented (e.g. ESPON TranSMEC). Priority 2 Targeted Analysis projects were in the focus as they are developed together with regional stakeholders. In this respect these projects already reflect the needs of regions and practitioners. In total 15 Priority 2 Targeted Analysis projects were selected for further review due to their potentially high relevance for detecting territorial potentials and challenges in different regions and cities around Europe 4 .

The projects' (draft) final reports were reviewed systematically. All reports were retrieved from ESPON's homepage in their latest available version. Although easily accessible online, the content of the reports differs significantly and in some cases relevant information, e.g. concerning concepts and methods, and how they have been developed and applied in the project, is difficult to access.

By focusing on the analytical and methodological approach used in the projects, the review aimed at understanding the relation between concepts, indicators and methods based on the rationale that a concept is analysed through indicators using specific (qualitative or quantitative) methods. It was important in the first place to identify the key concept(s) that was/were applied in the respective project (e.g. polycentricity, regional integration, territorial capital, territorial cohesion, globalisation, governance, institutional capacity) and to see how the concept had been operationalized (e.g. expressed by a number of related analytical sub-concepts such as functional urban areas, cross border integration, territorial assets, regional innovations, network connectivity). The projects were also reviewed in terms of use of indicators (e.g. GDP, commuting patterns, firm locations, leadership, patents) in relation to the concept(s) as well as methods of analysis (e.g. benchmarking, SWOT analysis, flow analysis).

To filter and analyse the key concept(s), to understand the motivation of choosing these concepts as well as how these were operationalized in the project was a challenging task. Most ESPON projects have adopted several analytical concepts, different more or less innovative methods and a wide range of indicators. There are a range of different concepts being used within ESPON, starting with mega-concepts such as globalisation, urbanisation, sustainable development, smart specialisation, as well as sub-concepts with a high degree of operability, that is - the operationalized concepts. It is occasionally difficult to distinguish between themes of indicators and concepts as in the case of governance and demography. The definition and usage of concepts are to a large degree dependent on the general character (i.e. micro-, meso- or macro- concepts) and the territorial scale of their applicability (e.g. European, national, regional or local).

Finally, based on the project reviews, innovative ESPON methods of analysis were identified. A focus in the method reviews was thus the innovative aspect of the projects, and their relevance for detecting territorial potentials and challenges. For example, the question addressed was whether the ESPON project developed a new and/or revised method (i.e. EATIA, TPM, SS-LR), or the project used or combined existing methods in innovative ways (i.e. METROBORDER, POLYCE).

\footnotetext{
4 These are bolded in appendix 1 to this publication.
} 
All in all twelve methods have been identified:

- Assessing functional integration

- Assessing polycentric development

- Attractiveness indexes

- Cross-border institutional mapping

- Econometric analysis of agglomerations

- Multilevel governance analysis

- Spatial scenarios

- Territorial impact assessment

- Territorial performance monitoring

- Territorial profiling and performance

- Understanding differential growth

- Urban growth modelling.

The relation between European experiences and ESPON knowledge provides on the one hand response for regional challenges as well as supplies practitioners and policy makers with knowledge. On the other hand this relation became the inspiration in developing the conceptual framework. It was the link between the research-oriented systematisation of analytical approaches and methods, the regional application and laboratories, and the synthesising and knowledge transfer. The conceptual framework combines territorial approaches, concepts, themes and methods multi-directionally, allowing for different paths to generate knowledge on territorial potentials and challenges. In order to display the multiple interlinkages between the different layers and types of information and to enhance usability, the conceptual framework was designed and presented in a flexible and interactive way.

A key issue in developing the conceptual framework (and the handbook) had been to identify the target group of the guide and the scope for its applicability, which were defined as:

- Policy makers and practitioners in the field of regional development or spatial planning, who are in an executive, leading position, making strategic decisions at regional level.

- The guide is most likely to be used in long-term strategic development, e.g. to support the creation and/or evaluation of regional development plans and programmes.

In order to meet the diverse requirements of the knowledge demand from these regional stakeholders and the complexity of approaches and methods, the framework (and the interactive handbook) presents information in a structured manner, at the same time offering different paths to knowledge generation. The linkages between territorial approaches, concepts, themes and methods are presented in a clear, graphic way, offering the user the possibility to navigate along logical chains. The interactivity allows to "jump" between different information outputs and levels of information, which enhances applicability and fosters the readability.

Regional laboratories for assessing the regional applicability of the conceptual framework are being set up across Europe in six regions of various size and characteristics.

The aim of this paper is to present scientific approaches to selecting methods and conducting regional laboratories, as well as to present the results regarding applicability of ESPON methods and knowledge in local and regional context. 


\section{Innovative ESPON methods for practitioners and policy makers}

One of ESPON's most important responsibilities is providing practitioners and policy makers working regionally or locally with resources for understanding their region's spatial dynamics, potentials and challenges. This includes the region's position within wider territorial contexts such as cross-border links, macro regions, and Europe as a whole. As a component of these resources, the methods identified in the ESPON DeTeC project offer good ways for practitioners to think about how to connect policy issues with analytical methods.

Ten innovative analytical methods that practitioners and policy makers can apply to detect their territorial challenges and potentials were identified. Analytical methods can be simple to implement, using readily available data and only requiring a few steps, or they can be much more complex, requiring detailed data and consultation with experienced experts. However, this difference does not always determine the value the method offers to practitioners in each region. This value is, instead, determined by the characteristics and important policy issues the region is facing.

Assessing functional integration is a method that has been developed within the ESPON METROBORDER project, which explored European cross-border and metropolitan regions in relation to the policy concept of polycentric development. The project goal was to identify criteria, potentials and governance practises for polycentric cross-border metropolitan regions, including recommendations for development strategies in two case regions: the Upper Rhine Region and the Greater Luxembourg Region (cf. ESPON 2010e).

Functional integration must be understood in terms of cross-border interaction and convergence between regions. While interactions strictly consider flows and barriers, convergence is about whether two regions are converging socially and economically. An important research question is whether increased cross-border commuting volumes (perhaps due to new transport connections) lead to regions converging socio-economically or a further deepening of imbalances.

Assessing polycentric development is a method that has been developed within the ESPON POLYCE project that has analysed five central European capital cities in relation to the concepts of metropolisation and polycentrism. The project emerged from the wish of city administrations for research on their future competitive and cooperative potentials, both among each other and towards other metropolises. The main goal was to conduct a comparative analysis of Bratislava, Budapest, Ljubljana, Prague, and Vienna, and their respective surrounding areas, in order to elaborate in-depth results on their specificities and commonalities (cf. ESPON 2012a).

This method is based on the concept of polycentricity, which describes how development can be spread between urban cores and secondary urban nodes in the periphery. These nodes are connected through different types of links that reduce functional distances. The links include physical links, such as transport connections and public service infrastructure, but also governance and firm networks. Polycentricity is a versatile concept, because it is evident at a number of scales. It can refer to the nodes that form within a neighbourhood, the urban core and neighbourhood nodes within a wider urban area, or the connections between urban regions within wider interregional, national and even international contexts.

Another method developed within the ESPON POLYCE project was urban growth modelling. What is the optimal size of cities? Are there different costs and benefits associated with urban development? These are especially important questions as cities are increasingly becoming urban agglomerations, functionally integrated metropolitan areas that are part of urban systems crossing 
administrative borders. Traditional understandings of place-based costs and benefits of urban development thus need to be complemented with non-conventional variables such as functional networks, sprawl, polycentricity, metropolisation and density.

An urban growth model offers an approach to answer the questions above through a cost-benefit analysis of city size. The results pertain to the issue whether a particular city-region should be bigger or smaller (in terms of population), considering how it performs in relation to determining factors of city size equilibrium. In turn, practitioners can discover which variables should be put in focus in order to achieve the greatest benefits from their investment.

Cross-border institutional mapping is a method that has also been developed within the ESPON METROBORDER project, see above. Development of territorial governance and institutional capacity is a complex process, especially in cross-border contexts, where very different institutional structures can exist. At the same time, fostering cooperation between and among public and private institutions as well as civil society is a crucial aspect of creating long lasting integration between cross-border regions. This method is useful for analysing the extent, to which these processes are taking place, and discovering new opportunities for collaboration by visualising the administrative authorities (local, regional, national and supra-national) and other relevant governance institutions involved in cross-border co-operation and their geographical scope. It combines visualisation techniques and categorisation of complex, multi-level political matters (cf. ESPON 2010e).

Multi-level governance analysis is a method that has been developed within the ESPON CAEE project. Effective multi-level governance arrangements within a region benefit from at least two prerequisites: good municipal co-operation paired with municipal autonomy to act upon agreed city-regional activities. Also, institutionalised regional governance can assume a leadership in policy development and ensure that higher governance levels recognise the economic importance of regions. Using this method, practitioners discover the roles in and relations between municipal, regional and national institutions, and the policies that have influenced growth and development within a region. This is done through workshops and interviews with key stakeholders, where the project has established three prerequisites that should be met for regions to fully exploit their capacity to influence economic growth: Low degree of local administrative fragmentation; Municipal autonomy and institutionalized Metropolitan governance (cf. ESPON 2010b).

Multi-level thematic territorial analysis is a method developed within the ESPON ULYSSES project which was an experimental and innovative project supported by 18 European border and cross-border areas. It aimed at using applied research results from ESPON as a benchmark for crossborder spatial development planning. The project performed six comprehensive and multi-thematic cross-border territorial analyses in cross-border regions in Europe (cf. ESPON 2013a).

As indicated by its name, the multi-thematic territorial analysis (MTA) investigates how development is taking place in regions according to general European policy goals, such as the Lisbon, EU 2020 and Gothenburg objectives. By doing so, it helps regions to identify which territorial aspects are most important for supporting this policy-driven development. The results can also be compared to more traditional qualitative decision-making tools, such as a standard SWOT analysis. MTA consists of two comprehensive steps which will most likely require the work of expert consultants: territorial profiling and measuring territorial performance.

Spatial scenarios is a method that has been refined within ESPON SS-LR, which aimed to update a spatial scenario model developed by ESPON 2006 (project 3.2), to build a new qualitative set of scenarios and to further develop a quantitative foresight model called MASST. A particular focus was placed on integrating recent societal trends and challenges, including the economic crisis, 
globalisation processes, the roles of emerging economies, energy trends, and new roles for rural areas. A concrete output of the project was the construction of spatial scenarios for the Spanish province of Barcelona, including a set of policy recommendations for future development (cf. ESPON 2010c).

Forecasting through scenarios can be hugely beneficial for spatial planning efforts, particularly as we deal here with decision-support tools that present information to a diverse audience. Therefore, the capacity to transfer methodologies of spatial scenarios to the local-regional scale is a subject of major relevance for regional development policy. Spatial scenarios are applied at the NUTS 2 level, but can also be applied in order to fine-tune foresight conducted at the NUTS 3 level. They help in reflecting the ways, in which global trends will impact territorial development of European regions.

The ESPON EATIA project further developed the territorial impact assessment method, which is a systematic framework for supporting national, regional and local administrations in anticipating the potential positive and negative impacts of EU directives. The aim was to develop models for avoiding potentially costly and negative impacts and to enhance economically, socially and environmentally positive outcomes for as many regions and localities as possible. Territorial impact assessment (TIA) provides the EU, its Member States and their regions with an understanding of regional and local consequences of European directives and other policy proposals. It is also used to detect opportunities for enhancing territorial governance (cf. ESPON 2012c).

The ESPON TPM project developed the territorial performance monitoring method. The project aimed at providing an assessment and development tool for regional monitoring of four major global challenges - demographic change, climate change, a new energy paradigm and globalisation. The tools within the project were applied in five stakeholder regions - Catalonia, Flanders, Greater Dublin, Navarre and North-Rhine Westphalia - with the aim of providing analytical support for strategy building by looking at how experiences can be shared and used in developing more effective territorial policy actions. Territorial performance monitoring starts with a mind mapping exercise, where global macro-challenges are translated into regional issues. Next, the regional issues must be translated into measurable indicators in order to allow for a permanent monitoring process (e.g. benchmarking against Europe). These indicators can be both qualitative and qualitative (cf. ESPON 2012b).

Translating macro-challenges into sub-national perspectives is increasingly important both for producing effective policies and for addressing challenges at the European level. Yet, placebased knowledge on some of the key macro-regional challenges (climate change, energy supply, demographic development and globalisation) is often limited and appropriate regional planning tools are rare. Through territorial performance monitoring a region can learn more about how macro-challenges are translated at the regional level and how to deal with these challenges effectively.

Understanding differential growth is a method developed within the ESPON SURE project, which has explored new ways of conceptualising and measuring imbalances within lagging European regions by searching for key indicators for understanding why specific regions lag behind while others accelerate their growth. This was achieved through a systematic comparison of factors relevant for economic growth and successful cohesion policy over the last 15 years in convergence regions (cf. ESPON 2012d).

The reasons why some regions continue to lag behind others while others are able to accelerate their economic growth are of key importance for the success of EU cohesion policy. Searching for the possible factors and finding systematic ways of comparing them, therefore, offers regional practitioners, who are charged with developing policy to improve the regional economic performance, a highly valuable tool. Not least, it provides an awareness raising mechanism on policy options available and how they can be implemented. 
The ESPON SURE project used a "stepwise, comprehensive and multilevel approach" to identify key factors accounting for differential growth in convergence regions. The result is a list of 14 factors in three categories that practitioners in convergence regions should consider when analysing the relationships between economic performance, growth opportunities, and the availability and implementation of EU funds.

\section{Regional laboratories}

The practice-oriented subject matter undertaken in this study to some extent imposed the range of research methods. In that way, in order to validate the conceptual framework and to assess its regional applicability, the case study based research method was adopted. The notions of knowledge co-production and information maximization (Flyvbjerg 2001), have been essential premises in this choice. Methodologically, the study has been structured around a participatory design as a knowledge-generating process (Bergold 2007), and according to Bergold (2012): "participatory research involves a joint process of knowledge-production that leads to new insights on the part of both scientists and practitioners". More precisely, a multiple-case design was used, enabling not only evaluation of theoretical concepts, but also comparisons and more nuanced interpretations of empirical phenomenon (Bhattacherjee 2012).

However, case studies can have many forms and can be applied in many contexts, therefore the regional laboratory can also be characterised as intervention in real-life context and a form of evaluation research (Yin, 2009). In this research, the "intervention" is related to the assessment of the conceptual framework (with territorial approaches and ESPON methods) in real-life circumstances. What is more, the multiple-case study approach also allows for comparisons between different cases and for discussion regarding the general applicability of different approaches and methods.

The regional laboratories have also been important nexuses in the learning process, which enabled moving to upper steps in the learning process, as, according to Flyvbjerg (2001), context independent knowledge and rules are crucial but only on the basic levels of the learning process. Thus, the additional knowledge gathered through the regional laboratory analyses, hence, through 'gaining the experience', complements the previous, theoretical knowledge. This learning process has been explicitly illustrated in the study with the theoretical constructs, elaborated, at first, and then tested through regional laboratories in the selected regions.

Being aware of the drawbacks of the case study approach (e.g. Benbasat et al. 1987), the selection process of the case study regions has been carefully planned in order to provide a set of cases representing various areas, problems and localisations within Europe. Furthermore, the regional laboratories organized in the selected case studies gathered a wide variety of stakeholders, practitioners and policy makers, who enriched the discussion and the assessment of the territorial approaches, providing the perspectives of different participants representing different institutions.

\section{Selection of case study laboratories}

The selection procedure was preceded by the creation of a list of potential case study regions, which have been previously involved in former ESPON projects. The main criteria of selection were, however, doubled. First of all, the aim was to represent different types of regions according to the ESPON territorial typology consisting of nine types: urban-rural; metropolitan regions; border regions; islands regions; sparsely populated regions; outermost regions; mountainous regions; coastal 
regions, as well as regions in industrial transition. Secondly, a balanced geographical coverage was deemed advisable, including regions located in the Northern and Western Europe, Central and Southern Europe, as well as in Eastern Europe. This criterion has also allowed for equal representation of regions regarding the old and new EU-member states.

Following the aforementioned criteria, six regions across Europe were selected as regional laboratories: Danube-Kris-Mures-Tisa Euroregion, Edinburgh South East Scotland, Malta, Podlasie, Skåne and Styria ${ }^{5}$ (Figure 1). The selected regions vary in terms of size, inner characteristics and administrative structure. The Danube-Kris-Mures-Tisa Euroregion is, for example, a border region of more than 3.4 million inhabitants including two Hungarian counties (Bács-Kiskun County, Csongrád County), three Romanian counties (Arad County, Caras-Severin County, Timis County) and the Autonomous Province of Vojvodina. Skåne is one unitary region with 33 municipalities and population of 1.2 million, Podlasie has similar number of population but consists of 118 municipalities and is located at the border of ESPON territory. The republic of Malta is a densely populated island, while Scotland, being a part of the United Kingdom, is a sparsely populated mountainous region.

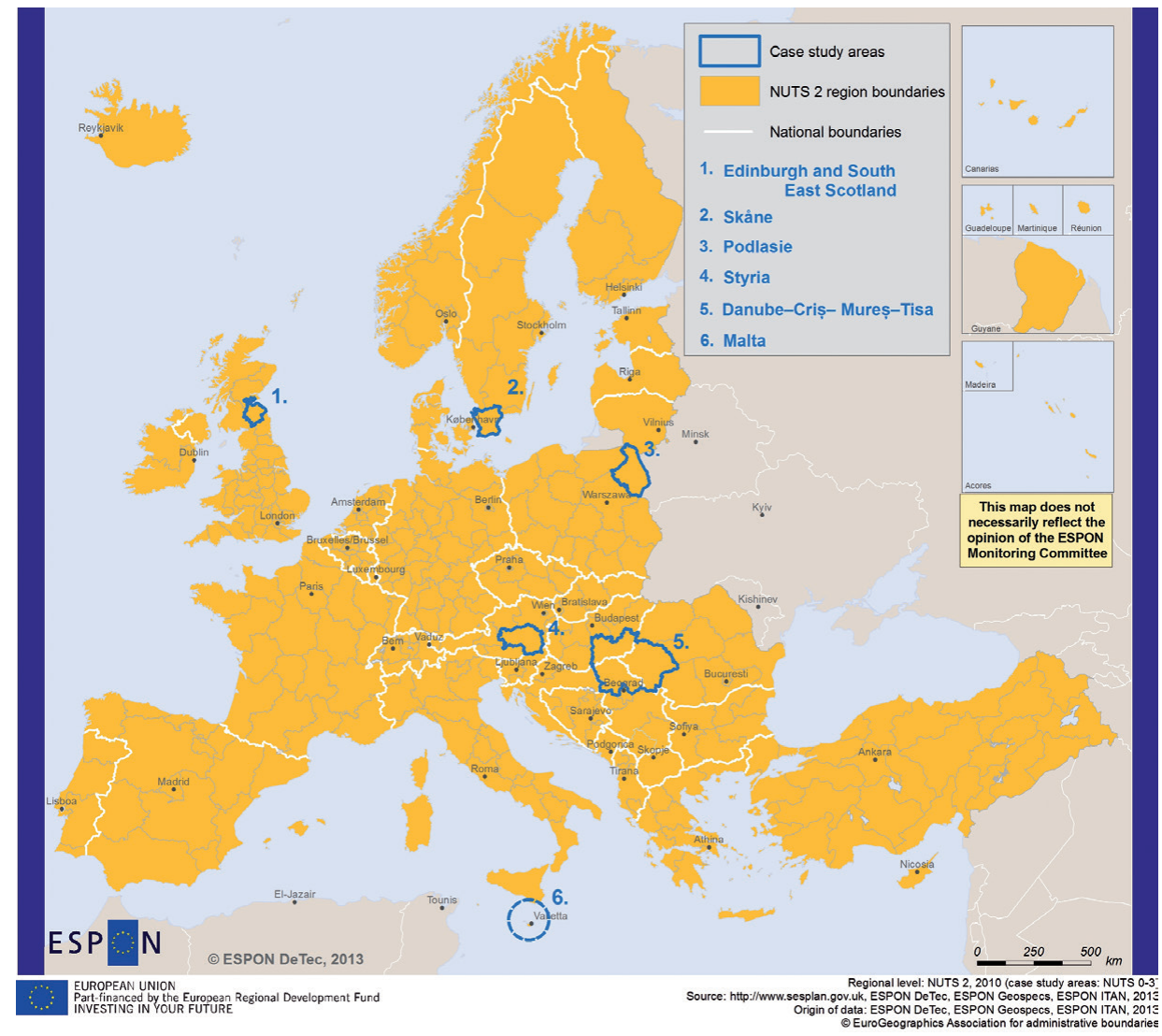

Figure 1. ESPON DeTeC case study areas

5 Apart from Styria, all the regions in question have been already involved in ESPON projects. In this context, the region of Styria plays a role of an external reference point for this research. 
The different regions also represent various administrative types with diversified governance structures. Podlasie, Skåne and Styria are all sub-national administrative regions. Edinburgh and South East Scotland is an emerging sub-national entity but also a part of United Kingdom. Malta is a sovereign state, while Danube-Kris-Mures-Tisa is a cross-border supra-national Euroregion. This diversity of regions selected has been considered as a key element in the assessment of the conceptual framework and the handbook's applicability in detecting territorial potentials and challenges in different types of regions.

Regional profiling constituted a proxy to positioning of regions in the wider European scene. There was also an underlying idea of presenting the performance of the selected regions on the basis of previous or on-going ESPON project results. However, the regional profiling faced numerous methodological difficulties. These concerned mainly the limited comparability of data within certain regions and thematic fields. Such a challenging task was to present the Danube-Kris-Mures-Tisa Euroregion, spreading over two EU countries (Hungary, Romania) and one non-EU country (Serbia). In this setting, the possibilities of collecting comparable information were quite limited. Moreover, even if the data concerning Hungarian and Romanian parts of the region were accessible, there were usually very strong divergences between them, making the overall assessment of regional economic performance extremely difficult. Nevertheless, the diversity of the case study regional laboratories allowed for verifying the applicability of territorial approaches in different regional but also political, economic and socio-demographic conditions.

\section{Regional profiles: quantitative overview}

The regional laboratories were preceded by the elaboration of a quantitative overview of selected regions, using a modified version of the "regional profiles" concept (developed in the ESPON RISE project). The idea of regional profiling combines regional characteristics and identification of region's performance. These regional profiles consisted of two parts. The first one was concentrated on quantitative and concise presentation of each region, based on comparable statistics issued from the European databases, piled in seven thematic sets: general characteristics, population, economy, education, infrastructure and accessibility, environment as well as land use.

In the second part, both quantitative and qualitative information were gathered in order to provide a broader approach, allowing for positioning of each region in relation to the others and within the European space. The characteristics of the regions were based on secondary materials in the form of statistical data, surveys and policy documents. This part of regional profiling was composed of similar thematic sets as those mentioned in the first part, with the focus on the comparability of performances between the regions. Using the knowledge from the previously prepared research, the positioning of the case study regions both in Europe and with regard to each other, was possible.

\section{Regional laboratories: qualitative approach}

After having selected the case studies and having elaborated regional profiles, the procedure of regional laboratories could have been commenced. According to Flyvbjerg "concrete experiences can be achieved via continued proximity to the studied reality and via feedback from those under study" (2001, p. 72). Following this statement, the organization of regional laboratories has been carried out in collaboration with the established local and regional contacts. The aim of these laboratories was thus to benefit from mutual exchange of knowledge: project partners disseminated the ESPON knowledge, presented the conceptual framework and provided examples of good practices while the practitioners and policy makers contributed with their regional knowledge in analysing the potentials and challenges. Conceived in such a manner, the laboratories were planned as a mode of collecting 
materials and obtaining practitioners' perspectives and assessment with regard to the content-oriented purpose. Obviously, laboratories took place in the specific case study regions.

The regional laboratories were also considered as a way of verification of the level of transferability of various methods and analytical approaches that have been proved to be relevant for detecting territorial potentials and challenges. This specific role was attributed to the interactive handbook, whose content and applicability was evaluated during the regional laboratories. In addition, the laboratories were used to receive feedback on the handbook and assessment of its applicability and the level of its utility in the daily work of stakeholders. This was also an occasion to present the ESPON 2013 program. Thus, the regional laboratories verified the possibility of vertical (from pan-European and national to regional and local levels) and horizontal (between different regions) transfer of knowledge in Europe. The regional laboratories have been conducted in two steps: a target group meeting and a stakeholder workshop.

\section{Target group meeting}

The target group meetings constituted the first part of the regional laboratories' methodology. They aimed at gathering key stakeholders from the region, practitioners and policy makers involved in strategic regional planning and regional development. Although a common structure for all target group meetings had been established, certain adaptations were required due to the specific regional setting. The scenarios for the target group meeting covered few steps.

The beginning of the target group meetings focused on taking advantage of previously developed materials within ESPON projects. This was especially important in the case when the participants of the meeting were not aware of specific topics undertaken within the ESPON programme. This included the presentation of regional profiles. With regard to the specificity of the region and to the participants in the meeting (their level of awareness of the ESPON projects), the presentation of regional profiles was rather flexible.

In the next step of the target group meeting the ESPON DeTeC project was presented including the explanation of the conceptual framework. This was followed by discussions concerning the territorial approaches. According to the specificity of each region being under investigation in this project, the partner in the project, responsible for the laboratory, selected a set of territorial approaches that were most relevant to the needs of the region. This selection had to be justified on the basis of the knowledge about the region, gained through the desktop research before the laboratories had started. In that way, the researchers (partner teams) presented solely the selected territorial approaches, explaining their basis and their applicability in the region. This applicability was understood in the two time scales: in daily work (addressing the most pressing issues) and on the long-term basis.

The target group meetings were assumed to be interactive and to provide the outputs concerning the needs of the participants. For this reason, the invited region's representatives were asked to comment on the selection of the priority territorial approaches and their applicability from their perspective as regional key players. The assessment of the territorial approaches was referring to their applicability, completeness and significance. The added value of these target group meetings laid also in the possibility to broaden the issues that territorial approaches were dealing with by the provision of additional intrinsic questions. The outcome of the target group meeting was a selection of the territorial approaches (perhaps the same as proposed by the partner team) that were then assessed using the application during the stakeholders' workshop. 


\section{Stakeholder workshop}

The regional workshops dedicated to the regional stakeholders were preceded with a brief presentation of the ESPON programme and the DeTeC project, as their gathered different public that was present during target group meetings. Subsequently, the summary of the previous meeting was presented, including the following issues: questions previously raised and the presentation of selected territorial approaches that would be tested during the on-going workshop. The workshops were designed for an in-depth presentation of the methods within each of the selected approaches, relevant for each region. The modes of evaluation of the approaches have varied across the regions regarding the number and background of stakeholders gathered. In some cases, the workshops gathered similar participants (at least some of them) as the previously carried out target group meetings, which is one of the commonly applied techniques in focus groups to encourage the conceptualization (see Morgan et al. 2008). Each group of stakeholders assessed the applicability and relevance of the methods presented with respect to their region, through precise rating grid or through brainstorming (in groups with numerous participants), named "professional discussion forum". These covered also the illustrative examples presented of how regions can make use of their territorial potentials.

In order to build interactions based on sharing and comparing thoughts about the topic, the workshops contained three stages: introduction was designed to mainly summarise the outcomes of the previous target group meeting and to emphasize the topics that would be then discussed. The assessment of the methods presented was the second phase, involving the participants and encouraging them to share their opinions. Finally, the third stage was practical to some extent, as the participants could have the opportunity to verify the preliminary version of the handbook.

In the final part of the workshop, the attention was paid to the handbook. The aim of this part was to collect opinions and critical remarks from the stakeholders concerning this guide. During the stakeholders' workshop, only the draft version of the handbook was presented as the elaboration was still in progress. For this reason, the participants of the workshop were not able to examine all the options.

\section{Applicability of ESPON methods in regional context}

Through conducting workshops in the regions, the project gained not only the knowledge regarding the technical issues related to the Handbook, but, above all, had the opportunity to present the methods and results developed in the ESPON program and to confront them with regional and local needs.

As emphasized repeatedly during the workshop, as well as already noted during the assessment of ESPON and workshops in other projects, maps and ESPON results are adequate to draw conclusions at a higher level than regional. The results from the regional laboratories show that the conceptual framework, consisting of territorial approaches and methods of analysis, developed within the DeTeC project, was deemed interesting from the regional point of view. However, in many cases, the stakeholders initially perceived the territorial approaches as too general and vague.

Interviews with participants of the workshop allowed for selecting the most important territorial approaches for individual regions. The regular interest in specific TA shows that the selection of regions was carried out in a proper manner. In some regions, certain TA were more interesting for stakeholder than others. In Edinburgh and South East Scotland, for example, especially the territorial approach Detecting global and future challenges and potentials of a region, was perceived as relevant for focusing on long-term macro challenges in parallel with more short-term pressing issues. Similarly 
in Malta, the above mentioned territorial approach was assessed as relevant, especially in relation to preparation of the Strategic Plan for the Environment and Development.

Table 1. Most relevant territorial approaches selected by regional representatives

\begin{tabular}{|l|c|c|c|c|c|c|}
\hline Region & Styria & Malta & Podlasie & $\begin{array}{c}\text { DKMT } \\
\text { Euroregion }\end{array}$ & Skåne & $\begin{array}{c}\text { Edinburgh South } \\
\text { East Scotland }\end{array}$ \\
\hline $\begin{array}{l}\text { Derritorial approaches } \\
\text { challenges and potentials of a region }\end{array}$ & $\mathrm{X}$ & $\mathrm{X}$ & & & $\mathrm{X}$ \\
\hline $\begin{array}{l}\text { Detecting and comparing territorial } \\
\text { performance of a region }\end{array}$ & $\mathrm{X}$ & $\mathrm{X}$ & $\mathrm{X}$ & & & \\
\hline $\begin{array}{l}\text { Detecting the functional areas and } \\
\text { internal coherence of a region }\end{array}$ & & $\mathrm{X}$ & $\mathrm{X}$ & & $\mathrm{X}$ & \\
\hline $\begin{array}{l}\text { Detecting current and potential } \\
\text { external linkages of a region }\end{array}$ & & & $\mathrm{X}$ & $\mathrm{X}$ & $\mathrm{X}$ & \\
\hline $\begin{array}{l}\text { Detecting opportunities for } \\
\text { territorial governance of a region }\end{array}$ & & & & $\mathrm{X}$ & $\mathrm{X}$ & $\mathrm{X}$ \\
\hline
\end{tabular}

Detecting and comparing the territorial performance of a region was considered relevant in Malta, Styria and Podlasie. The analysis, which had already been performed by regional stakeholders, shows that Podlasie should concentrate on reinforcing the economic drivers of the region, including accessibility, human capital, and quality of life. The results also show that there is a need to seek for effective solutions for over-dependence on agriculture. In Styria it is relevant in the case of preparing sustainable spatial strategy for the development of the region - stakeholders thought that ESPON knowledge could help in that case.

Detecting the functional areas and internal coherence of a region was relevant in Malta, Podlasie and Skåne. In those regions, functional as well as spatial integration is one of the main issues for promoting territorial cohesion.

Detecting current and potential external linkages of a region was relevant for the DKMT Euroregion, Skåne, Podlasie. The regional stakeholders underlined that it could be interesting to expand the territorial perspective beyond the region of Skåne, and explore new larger geographies. Links and cooperation with neighbouring regions was highlighted as a key issue, such as more cooperation around the Öresund region with the Öresund Committee and with the capital region of Copenhagen, to make Skåne an integral part of the Öresund region in accordance with the regional development programme.

Detecting opportunities for territorial governance of a region was interesting for Skåne, DKMT Euroregion, Edinburgh and South East Scotland. Scottish case shows that South East Scotland as a city region is a new regional setup and that authority South East Scotland Plan is a new constellation as well.

The last two TAs were relevant for the DKMT Euroregion, what shows the trans-national nature of the Euroregion, where the unique geo-political circumstances are reflected in the very specific character of the Euroregion.

During the second meeting with the regional representatives (stakeholder workshop) in each region the most appropriate methods of analysis were presented, which potentially could be used to deal with key challenges identified at the first meeting. The figure below (figure 2) presents the exemplary concept of applying the DeTeC's territorial approaches and methods of analysis in the process of 
detecting territorial potentials and challenges. The researchers involved in DeTeC were inspired by the experience of previous ESPON projects, which has been systemized in Table 2, presenting the application of methods in a regional context. The most significant element, which was highly appreciated by regional representatives were the illustrative examples of regional good practices.

In order to provide concrete examples of good practices in utilising territorial potentials and/or deal with particular challenges, which is one of the objectives of the project, it is necessary to formulate what good practice entails. First of all a clarification of distinction between good and best practices, words often used interchangeably and confusedly in policy documents and guidelines, is in order.

In general terms, a best practice is a superior method or action that contributes to the improved performance of an organisation, and as such is usually recognised as 'best' by other peer organisations. Applying best practice is the best method to reach well-defined objectives. Best practice documents may include guidelines, codes of practices, procedure manuals, and regulations. On the other hand, good practice is more related to the accumulation and application of knowledge about what is working and not working in different situations and contexts, including lessons learned and the continuing process of learning, feedback, reflection and analysis (what works, why and how). (Related to the case studies and stakeholder involvement, and perhaps communities of practice, as well as learning regimes).

Good practices are thus difficult to define a priori but can be identified in conjunction and in collaboration with stakeholders. For this project this means that the concrete examples of good practices of utilising will primarily be derived from the case studies, i.e. what works in practice. However, the systematic review will give indications and set up certain basic criteria of good practices and potential examples of good practices in utilisation of territorial potentials.

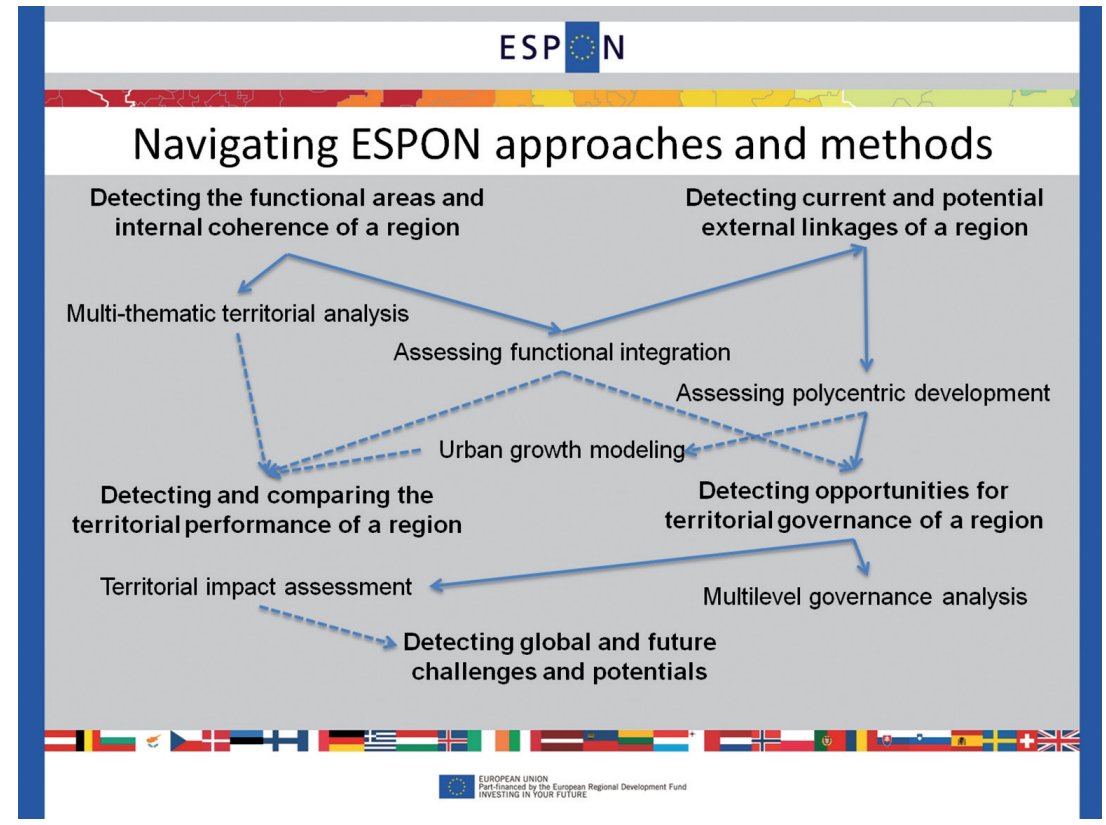

Figure 2. An illustration of how territorial approaches and methods could be used and interconnected to detect territorial potentials and challenges of Skåne region.

Source: presentation from Stakeholder Workshop in Skåne region. 
In the process of developing and practical use of the handbook as well as during discussions with regional representatives, some relevant "good practices" have been observed that show how territorial approaches and methods of analysis can be combined with each other in various manners. The methods implemented in past ESPON projects correspond to the diverse territorial approaches, and due to such relations they may meet the practitioners' needs. Illustrative examples can potentially inspire regional policymakers to conduct analyses based on methods applied in ESPON projects. The interactive handbook and therein included descriptions of methods and "good practices" will successfully facilitate the stakeholders' work on detecting regional potentials and challenges.

Table 2. Innovative ESPON methods and their application in the regional context

\begin{tabular}{|l|l|c|}
\hline Method & Regional Lab & $\#$ \\
\hline 1) Assessing functional integration & Skåne Region & 1 \\
\hline 2) Assessing polycentric development & Malta, Skåne Region, Podlasie, DKMT Euroregion & 4 \\
\hline 3) Cross-border institutional mapping & Podlasie, DKMT Euroregion & 2 \\
\hline 4) Multilevel governance analysis & $\begin{array}{l}\text { Edinburgh and South East Scotland, Skåne Region, } \\
\text { DKMT Euroregion }\end{array}$ & 3 \\
\hline 5) Multi-thematic territorial analysis & Malta, Styria, Skåne Region & 3 \\
\hline 6) Spatial scenarios & Malta & 1 \\
\hline 7) Territorial impact assessment & Malta, Styria, Skåne Region & 3 \\
\hline 8) Territorial performance monitoring & Edinburgh and South East Scotland & 1 \\
\hline 9) Understanding differential growth & & 0 \\
\hline 10) Urban growth modelling & Skåne Region, Podlasie & 2 \\
\hline
\end{tabular}

According to the discussions within the regional laboratories, ESPON methods are principally interesting from a regional point of view. Especially the methods of assessing polycentric development, multilevel governance analysis, multi-thematic territorial analysis and territorial impact assessment can be of relevance in regions and can therefore contribute to improved decision-making.

For example, ESPON provides user-friendly tools (e.g. ESPON ARTS quick-check; TIA Web-tool) for the purpose of conducting territorial impact analysis. Multilevel governance analysis is considered to represent a feasible method to analyse transnational cooperation and to detect relations between municipal, regional and national institutions. The method of assessing polycentric development can not only be used to detect polycentricism, but can also contribute to supporting sustainable development of a region. In one of the regional laboratories it was concluded that it could be possible to identify the type of polycentricism that has developed within a region (morphological, relational, polycentricism in governance) and so regional development could be targeted more efficiently.

Regions which have been established for a long time and which already have defined their development perspectives very well (e.g. Styria), are the most critical towards ESPON and the possibility of applying innovative methods in their daily work. This might be due to the fact that these regions have their common objectives, well established institutional settings and usually apply their own approaches and methods in defining challenges and potentials.

On the other hand, mainly "new" regions - as for example Edinburgh and South East Scotland (being established in 2006, consisting of six council areas) - as well as quite large regions - as for 
example the DKMT Euroregion - were very interested and positive towards ESPON methods. In Edinburgh and South East Scotland recently the Strategic Development Plan 1 for the city region was prepared, approved by the Scottish Government in June 2013 and setting a vision for the city region. The DKMT Euroregion was already established in 1997 and represents a cross-border cooperation area, in which Hungary, Romania and Serbia are participating.

These two examples illustrate that both regions feature a very specific governance approach that differs from the one established, for example, in Styria, an Austrian federal state with a clear governmental approach.

The governance situation of regions may determine their willingness and ability to apply innovative methods. Additionally, ESPON projects may provide knowledge and findings more interesting for larger areas, as this knowledge and findings are mostly provided on NUTS 2 level - this will not be the case for a very small-scale region ${ }^{6}$.

However, some critical points were identified, which have major implications for the possible implementation of innovative methods in a more local or regional context:

Issues of applicability of ESPON analyses or methods in different spatial contexts as well as issues concerning data availability and comparability were raised during the regional laboratories: Especially for the local level as well as for regions of small scale, the scale of ESPON analysis and their methods is considered as being too coarse by regional stakeholders. Helpful findings may be provided by the application of analyses with data on NUTS 3 level or even below (LAU 1, 2).

Generally, ESPON methods are feasible for application on the regional level. Understanding the position of one's region or city in a larger territorial context opens up new possibilities for capitalising on territorial potentials. These larger contexts, provided by ESPON analyses, include relations with neighbouring regions, macro-regional contexts, a European perspective and the regional impacts of global issues. However, the availability of Europe-wide harmonised regional data is restricted. Regions often use similar methods in their regional analysis with region-specific data at a sometimes very high spatial resolution. In these cases, focussing on intra-regional trends and challenges, ESPON analyses do not provide added value for regions as they are at too high a spatial level.

It was also frequently mentioned that knowledge about ESPON methods needs to be better accessible, e.g. through more user-friendly publications, tools and websites. At the same time, there exists a demand for a more detailed explanation of methods and their results.

Generally, scepticism towards the application of ESPON methods at lower spatial levels or in different contexts may be held against that innovative ESPON methods, presented in the ESPON $\mathrm{DeTeC}$ project, may serve as inspiration for local and regional stakeholders and need to be translated to lower scales.

As a consequence of the various activities performed within the DeTeC project it can be concluded that methods and approaches developed within ESPON are of relevance for regional and local stakeholders, although there exist significant challenges in applying and using ESPON approaches, methods, tools and indicators at regional and local levels, depending on the region's governance settings and characteristics.

\footnotetext{
${ }^{6}$ Example: The government of Styria (Styria being one of the NUTS 2 regions of Austria) would be interested in the analysis of regional hotspots of R\&D expenditure (e.g. NUTS 3 level, urban hinterlands, etc.). ESPON findings on NUTS2 level are very well suited for allowing a European overview, but for this specific question, analyses need to be applied at a much more detailed spatial level in order to be of added-value for regional stakeholders.
} 


\section{Conclusions}

There are a number of future research and policy challenges (and potentials). In the DeTeC project two types of challenges (and potentials) have been identified, both regarding the production of ESPON knowledge and its application. The first type has mainly been deducted from the reviews, analysis and systematisation of ESPON, while the second derives from the regional laboratories and the engagement with local and regional stakeholders. It is thus possible to distinguish between future research gaps, opportunities and regional policy challenges.

There is a general critique voiced by the ESPON community that advanced territorial and comparable analysis of European space is for the most part limited, since a large number of valid data is only available for relatively large territorial units. The claim for harmonised data to analyse and compare in particular small territorial units (e.g. at the neighbourhood level) has been put forward at various opportunities. This claim is, however, contested, in particular since empirical evidence stemming from social science work (as it inevitably does within ESPON) normally allows for various interpretations and policy options and, due to this, cannot be considered as an unambiguous guide to policy making.

One of the key issues concerning application of knowledge gained in the ESPON program is the scale of presented results. In order to detect territorial potential and regional challenges not only the knowledge of the external conditions is essential but also the identification of intraregional factors appears to be crucial. Concepts used within ESPON (analyses, typologies, classifications) - on the whole - refer to large spatial units, hence the general nature of the scale of outcomes rarely enables consideration of intraregional diversity.

\section{References:}

Benbasat I., Goldstein, D. K., Mead, M., 1987, The Case Research Strategy in Studies of Information Systems, MIS Quarterly (11:3), pp. 369-386.

Bergold J. \& Thomas S., 2012, Participatory Research Methods: A Methodological Approach in Motion, Forum Qualitative Sozialforschung / Forum: Qualitative Social Research, 13 (1). Art. 30, http://nbn-resolving.de/urn:nbn:de:0114-fqs1201304 [1 February 2014].

Bergold J., 2007, Participatory strategies in community psychology research—a short survey. [in:] A. Bokszczanin (ed.), Poland welcomes community psychology: Proceedings from the 6th European Conference on Community Psychology Opole, Opole University Press, pp.57-66.

Bhattacherjee A., 2012, Social Science Research: Principles, Methods, and Practices, USF Tampa Bay OpenAccess Textbooks Collection, Book3, 153 pp.

ESPON 2010a, ESPON TEDI: Territorial Diversity (Final report: 12 May 2010). http://www.espon. eu/main/Menu_Projects/Menu_TargetedAnalyses/espontedi.html (1 February 2014].

ESPON 2010b, ESPON CAEE: The case for agglomeration economies in Europe (Final report: 30 June 2010). http://www.espon.eu/main/Menu_Projects/Menu_TargetedAnalyses/CAEE.html [ 1 February 2014].

ESPON 2010c, ESPON SS-LR: Spatial Scenarios - new tools for local-regional scenarios (Final report: 27 July 2010). http://www.espon.eu/main/Menu_Projects/Menu_TargetedAnalyses/ SS_LR.html [ 1 February 2014]. 
ESPON 2010d, ESPON SURE: Success for Convergence Regions' Economies (Final report: 24 December 2010). http://www.espon.eu/main/Menu_Projects/Menu_TargetedAnalyses/SURE. html [ 1 February 2014].

ESPON 2010e, ESPON METROBORDER: Cross-border polycentric metropolitan regions (Final report: 31 December 2010). http://www.espon.eu/main/Menu_Projects/Menu_TargetedAnalyses/ metroborder.html [ 1 February 2014].

ESPON 2011, ESPON EUROISLANDS: The Development of Islands - European Islands and Cohesion Policy (Final report: 1 August 2011). http://www.espon.eu/main/Menu_Projects/Menu_TargetedAnalyses/EUROISLANDS.html [ 1 February 2014].

ESPON 2012a, ESPON POLYCE: Metropolisation and Polycentric Development in Central Europe (Final report: 31 May 2012). http://www.espon.eu/main/Menu_Projects/Menu_TargetedAnalyses/polyce.html [ 1 February 2014].

ESPON 2012b, ESPON TPM: Territorial Performance Monitoring (Final report: 29 June 2012). http:// www.espon.eu/main/Menu_Projects/Menu_TargetedAnalyses/TPM.html [ 1 February 2014].

ESPON 2012c, ESPON EATIA: ESPON and Territorial Impact Assessment (Final report: 29 June 2012). http://www.espon.eu/main/Menu_Projects/Menu_TargetedAnalyses/EATIA.html [1 February 2014].

ESPON 2012d, ESPON PURR: Potential of Rural Regions (Final report 30 June 2012). http://www. espon.eu/main/Menu_Projects/Menu_TargetedAnalyses/purr.html [ 1 February 2014].

ESPON 2012e, ESPON RISE: Region Integrated Strategies in Europe (Final report: 13 July 2012). http:// www.espon.eu/main/Menu_Projects/Menu_TargetedAnalyses/rise.html [ 1 February 2014].

ESPON 2012f, ESPON SMART-IST: Institutional Capacity for Territorial Development (Final report: 30 September 2012). http://www.espon.eu/main/Menu_Projects/Menu_TargetedAnalyses/smartist.html [ 1 February 2014].

ESPON 2013a, ESPON ULYSSES: Using Applied Results from ESPON as a yardstick for crossborder spatial planning and development (Final report: 25 January 2013). http://www.espon. eu/main/Menu_Projects/Menu_TargetedAnalyses/ulysses.html [ 1 February 2014].

ESPON 2013b, ESPON BEST METROPOLISES: Best Development Conditions in European Metropolises: Paris, Berlin and Warsaw (Final report: 29 January 2013). http://www.espon. eu/main/Menu_Projects/Menu_TargetedAnalyses/bestmetropolises.html [ 1 February 2014].

ESPON 2013c, ESPON KITCASP: Key Indicators for Territorial Cohesion and Spatial Planning (Draft final report: 31 July 2013). http://www.espon.eu/main/Menu_Projects/Menu_TargetedAnalyses/kitcasp.html [ 1 February 2014].

ESPON Database Portal, http://database.espon.eu/db2/home [ 1 February 2014].

Flyvbjerg B., 2001, Making Social Science Matter: Why Social Inquiry Fails and How it Can Succeed Again. Cambridge University Press, Cambridge, 212 pp.

Morgan D.L., Fellows C.E., Guevara H., 2008, Emergent approaches to focus groups research. [in:] S.N. Hesse-Biber, P. Leavy (eds), Handbook of emergent methods, Guilford Press, New York, pp. 189-206.

Regional Use of ESPON Knowledge, 2010, Working Paper from the internal ESPON Seminar 3-4 December 2009 in Malmö. http://www.espon.eu/export/sites/default/Documents/Publications/ SeminarsReports/Malmoe_Seminar_Report.pdf [3 March 2014].

Yin R.K., 2009, Case Study Research, Design and Methods, vol. 5, Thousand Oaks, California, SAGE Publications, pp. 93- 101. 


\section{ALL VOLUMES OF EUROPA XXI}

23 (2013) : Services of General Interest in European Union

22 (2012) : Territorial development and cohesion in a multi-scalar perspective

21 (2010) : Environmental and infrastructural networks

20 (2010) : European Union: external and internal borders, interactions and networks

19 (2009) : European urban system: metropolization and networking

18 (2008) : Territorial dilemmas of socio-economic development in Europe

17 (2008) : New functions of rural and industrial space in Central and Eastern Europe

16 (2007) : Regional development in Central Europe - cohesion or competitiveness

15 (2006) : Regional periphery in Central and Eastern Europe

14 (2006) : Core and peripheral regions in Central and Eastern Europe

13 (2005) : New spatial relations in new Europe

12 (2005) : Central and Eastern Europe: changing spatial patterns of human activity

11 (2004) : Przestrzeń Europy. Przestrzeń Unii Europejskiej

10 (2003) : Society and environment. Towns and settlement in Europe

9 (2003) : Polska i Europa: kształtowanie przestrzeni wolności

8 (2003) : European space in the face of enlargement: the West to East European Trajectory project

7 (2002) : Slovakia and Poland: urban, social and demographic questions, relations between neighbours

6 (2001) : Integracja europejska - dylematy spójności i konwergencji regionalnej

5 (2000) : Przestrzeń ekologiczna Polski. Dekolektywizacja rolnictwa i sytuacja zdrowotna w Europie Środkowej, Wschodniej i Południowo-Wschodniej

4 (2000) : Powiązania handlowe Polski z Europą. Z debaty o przyszłym kształcie zjednoczonej Europy

3 (1999) : Obszary szczególnej troski i nowych możliwości rozwoju na przykładzie Polski i Ukrainy

2 (1998) : Przestrzeń Europy Środkowej - przykłady transformacji

1 (1998) : Sieć komunikacyjna Polski w europejskich procesach integracyjnych 


\section{Applicability of ESPON knowledge in regional and local context}

- Michał Konopski

The role and significance of regional policy in Europe

- Jerzy Bański, Mariola Ferenc

ESPON as a tool of national and regional policy

- Lukas Smas, Peter Schmitt

Making ESPON knowledge more tangible for detecting

regional potentials and challenges: five territorial approaches

- Christian Dymén, Stephanie Essig, Mariola Ferenc, Magdalena Górczyńska, Jiannis Kaucic, Michał Konopski, Stefanie Lange Scherbenske, Bernd Schuh Accessible ESPON knowledge and its application in local and regional context 